\title{
PADRÕES TÉRMICOS NO ALTO VALE DO ZÊZERE. CONDICIONANTES TOPOGRÁFICAS E METEOROLÓGICAS
}

CARLA MORA $^{1}$

\begin{abstract}
Resumo - Os climas das áreas de montanha são mal conhecidos devido à ausência de observações meteorológicas em posições topográficas diferenciadas. Esta lacuna foi colmatada nos Altos Planaltos da Serra da Estrela com a instalação de uma rede de postos termométricos automáticos que registaram a temperatura instantânea do ar em intervalos de 2 horas durante o ano 2000. Com uma classificação $k$-means foi possível agrupar as observações e identificar quatro principais padrões térmicos. Em dois padrões (2 e 3) registou-se a diminuição da temperatura com a altitude ( $66 \%$ dos casos). No entanto, além daqueles padrões mais comuns verificouse que, em $34 \%$ dos casos, os fundos dos vales estão mais frios do que os planaltos (padrões 1 e 4). No padrão 1 os lagos de ar frio ocorrem de noite e, no padrão 4 , mantêm-se durante a manhã. As causas da ocorrência dos diferentes padrões foram esclarecidas a partir da análise discriminante one-way ANOVA utilizando-se factores explicativos meteorológicos e topográficos. Esta mostrou que os padrões 2 e 3 estão associados a condições de instabilidade atmosférica, com velocidade do vento e humidade relativa superiores às registadas nos outros padrões e movimentos verticais das massas de ar mais intensos (ómega negativo). Pelo contrário, os padrões 1 e 4 estão associados a condições de estabilidade atmosférica. As variáveis com maior grau de explicação foram integradas na análise discriminante, que classifica correctamente $74 \%$ dos casos. A primeira função (71\%) discrimina os eventos nocturnos dos diurnos e a segunda (41\%) os eventos em função do grau de estabilidade atmosférica. Os resultados ilustram bem o efeito do relevo sobre as temperaturas do ar e poderão ser extrapolados para montanhas com condições climáticas e topográficas semelhantes. O conhecimento do efeito de sombra induzido pelos vales e a sua repercussão na manutenção dos lagos de ar frio durante a manhã em vales de orientação Norte-Sul é especialmente importante para o ordenamento e em estudos de impacte ambiental.
\end{abstract}

Palavras-chave: Padrões térmicos, temperatura do ar, clima local, Serra da Estrela, inversões térmicas.

Recebido: 25/11/2007. Revisto: 15/05/2009. Aceite: 04/06/2009.

1 Investigadora Auxiliar do Centro de Estudos Geográficos. Faculdade de Letras. Universidade de Lisboa. E-mail: csilvamora@gmail.com 


\begin{abstract}
Air temperature PATterns in UPPER ZÊZere VAlley (SERRA DA Estrela, Portugal). The influence of TOPOGRAPHY AND METEOROLOGY - A network of air temperature data loggers was installed in the Serra da Estrela with the objective of studying the main air temperature patterns. Data was collected at 2-hour intervals during 2000. A k-means analysis was used to classify the air temperatures and 4 types of patterns were identified. Patterns 1 and 4 that occurred in $34 \%$ of the records show cold air accumulation on valley floors. In Patterns 2 and 3 air temperature decreases with altitude (66\%). The control effect of the geographic and meteorological factors on the 4 temperature patterns was evaluated using one-way ANOVA. The results show that patterns 2 and 3 are related to unstable atmospheric conditions, with high wind speed and air humidity, and more intense vertical movement of the air (negative omega). On the contrary, the other two patterns are related to more stable atmospheric conditions ( 1 and 4$)$. The more significant variables from the ANOVA were chosen for the discriminant function analysis. The results model correctly $74 \%$ of the cases. The first function (71\%) discriminates nocturnal from diurnal events and the second (41\%), the atmospheric stability. The results evidence the effect of the morphology in the air temperatures and similar results are to be expected in mountains with comparable topographical and climate conditions. Knowledge of the shadow effect induced by the valleys and its repercussions on the maintenance of the cold air pool in the morning in N-S oriented valleys (pattern 4) is especially significant for planning and environmental impact assessment studies.
\end{abstract}

Key words: Temperature patterns, air temperature, local climate, Serra da Estrela, thermal inversions.

Résumé - LES TYPES DE RÉPARTITION DES TEMPÉRATURES DE L'AIR DANS LA HAUTE VALlÉE DU ZÊZERE (SERRA DA Estrela, PoRTUGAL). LEURS CONDITIONS TOPOGRAPHIQUES ET MÉTÉOROLOGIQUES. On a installé, dans la partie la plus élevée de la montagne, un réseau de postes thermométriques automatiques, qui ont enregistré les températures instantanées, de 2 heures en 2 heures, pendant l'année 2000. Une classification kmeans a permis de déterminer 4 types principaux de répartition thermique. En $66 \%$ des cas (types 2 et 3), la température diminuait avec l'altitude, en 34\% des cas (types 1 et 4 ), les fonds de vallée étaient plus froids que les plateaux. Dans le type 1, l'accumulation d'air froid était nocturne et, dans le type 4, elle se prolongeait le matin. L'analyse discriminante one-way ANOVA a permis de déterminer l'influence des facteurs météorologiques et topographiques. Les types 2 et 3 correspondent à des situations d'instabilité atmosphérique, marquées par une vitesse du vent, une humidité relative et un mouvement vertical de l'air (oméga négatif) supérieurs. Les types 1 et 4 correspondent au contraire à des situations de stabilité atmosphérique. $74 \%$ des cas ont été correctement classés par analyse discriminante. La première fonction (71\%) sépare les observations nocturnes et diurnes, et la seconde (41\%) les classe en fonction du degré de stabilité de l'atmosphère. Ces résultats montrent bien l'influence de la topographie sur les températures de l'air. Ils pourront être extrapolés à des montagnes présentant des conditions analogues. L'importance de l'ombre portée par les versants de vallées d'orientation méridienne, pour le maintien matinal des accumulations d'air froid, est surtout à prendre en compte dans les études de planification locale et d'impact environnemental.

Mots-clés: Types de répartition thermique, température de l'air, climat local, Serra da Estrela, inversion thermique. 


\section{INTRODUÇÃO}

A Serra da Estela faz parte da Cordilheira Central e é a montanha mais alta de Portugal continental $\left(40^{\circ} 20^{\prime} \mathrm{N}, 7^{\circ} 35^{\prime} \mathrm{W}, 1993 \mathrm{~m}\right)$. É constituída por dois planaltos principais, separados pelo alinhamento NNE-SSW dos vales do Zêzere e de Alforfa (fig. 1). Em pormenor os planaltos são constituídos por vários patamares cuja altitude diminui em direcção a NE. Os flancos NW e SE da Estrela são talhados em granito e têm um desnível acentuado, que aumenta em direcção a SW, onde ultrapassa os $800 \mathrm{~m}$. Os planaltos contactam com a área envolvente, em particular, a Cova da Beira e plataforma do Mondego, através de vales profundos e de vertentes com comandos que variam entre 200 e $700 \mathrm{~m}$.

A posição da Serra da Estrela, a sua altitude e topografia acidentada fazem com que seja uma área de grande interesse para o estudo do clima de montanha. Em Portugal, estes tipos de climas foram estudados ao nível regional por Daveau et al. (1977 e 1985) e Alcoforado et al. (1993a), tendo a última autora iniciado trabalhos de clima local nas serras de Sintra e da Arrábida (Alcoforado, 1994, 1984; Alcoforado et al., 1993b). O estudo dos climas locais da serra da Arrábida foi continuado por Mora (1998).

$\mathrm{Na}$ Serra da Estrela a inexistência de estações meteorológicas com séries longas de dados no sector mais elevado terá sido, em larga medida, a principal causa da falta de estudos climáticos, o que teve como consequência o fraco conhecimento do mosaico de climas locais da serra. Para ultrapassar esta limitação, iniciámos em 1999 a instalação de uma rede de postos termométricos. Foi assim possível estudar os padrões térmicos horários do ar nos planaltos e no alto vale do Zêzere e caracterizar os diferentes padrões térmicos da Serra da Estrela (Mora, 2006).

\section{METODOLOGIA}

Este estudo foi realizado com base na monitorização da temperatura do ar, com intervalos de registo curtos e usando uma rede de estações densa. Os registadores automáticos da temperatura do ar foram instalados em posições topográficas diferentes, de modo a documentar as principais características dos planaltos e vales interiores da serra da Estrela (fig. 1). A instalação da rede de registadores foi muito importante pois durante o período de estudo, só se encontrava a funcionar a estação meteorológica das Penhas Douradas $(1360 \mathrm{~m})$, o que é insuficiente para fornecer a informação necessária para os estudos do clima local.

Os registadores de temperaturas do ar, que designamos por postos termométricos, foram adaptados segundo os procedimentos descritos em Vieira et al. (2000). Os sensores termométricos foram instalados num tubo de PVC a 1,20m de altura. $\mathrm{O}$ sistema de registo é baseado em mini-loggers de 1 canal Tiny Talk (Gemini) com uma precisão de $0,35^{\circ} \mathrm{C}$. $\mathrm{O}$ posto foi desenhado de forma a per- 
mitir o arejamento, impedindo o aquecimento e arrefecimento do termistor relativamente ao meio.

Para este trabalho, foram utilizados dados de 7 postos termométricos com posições de fundo de vale e de interflúvio e que registaram dados em intervalos de 2 horas ao longo do ano 2000.

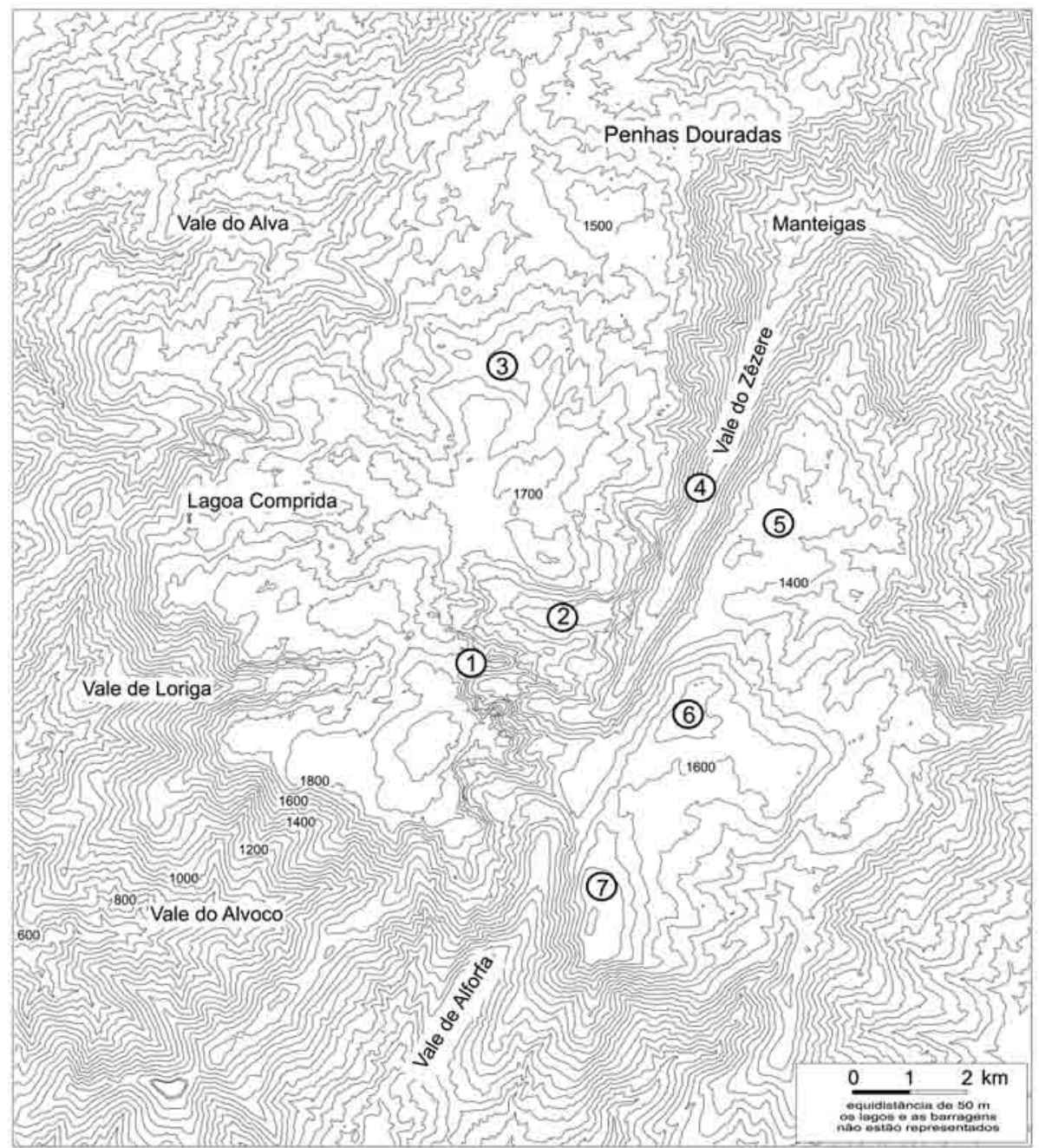

Fig. 1 - Localização dos postos termométricos instalados na Serra da Estrela:

1 - Cântaro Gordo - 1875 m, 2 - vale da Candieira - 1420 m, 3 - Fraga das Penas - 1630 m, 4 - Vale do Zêzere /ASE - 1080 m, 5 - Curral da Nave - 1425 m, 6 - Poios Brancos - 1675 m, 7 - Alto da Pedrice - 1735 m.

Fig. 1 - Location of the air temperature dataloggers in the Serra da Estrela. 
Existem várias formas de análise dos padrões de temperatura do ar, sendo mais frequentemente usadas aquelas em que se procuram encontrar os momentos do dia representativos das temperaturas mínimas ou das máximas diárias. Com o objectivo de explorar com detalhe as 12 observações diárias disponíveis, neste trabalho foram analisados todos os registos simultâneos de modo a avaliar as condições mais frequentes e as suas características. Este procedimento originou resultados mais satisfatórios do que os obtidos usando horas pré-definidas.

A comparação de dados em momentos distintos do ano foi feita a partir de diferenças de temperatura a uma estação de referência, método que permite a análise de dados registados ao longo do ano, de valores absolutos muito distintos. Aliás, o recurso a estações de referência é um procedimento seguido por vários autores em estudos de climatologia local (Alcoforado et al., 1993b; Hogan e Ferrick, 1997; Pepin e Losleben, 2002). Foi escolhido como posto de referência o Cântaro Gordo, por ser o que se situa a maior altitude e por estar numa posição de interflúvio e reflectir as condições meteorológicas do sector mais elevado da Serra, tendo, assim, um comportamento mais próximo das condições meteorológicas regionais (fig. 1). As diferenças de temperatura positivas indicam que o posto se encontrava mais quente do que o Cântaro Gordo.

Para identificar os principais tipos de padrões térmicos procedeu-se à aplicação de uma classificação por $k$-means às diferenças de temperatura dos postos termométricos em relação ao Cântaro Gordo. Esta técnica permite agrupar os indivíduos com comportamento próximo. Aplicou-se de seguida uma análise de variância (One-way ANOVA) que permite avaliar os factores geográficos e meteorológicos que determinaram a classificação dos padrões térmicos obtida (Wilks, 1995). As principais variáveis usadas correspondem à informação da estação meteorológica das Penhas Douradas, obtida a partir do Boletim Meteorológico Diário (IM) e aos dados das reanálises-1 do $N C E P / N C A R^{2}$, para uma janela com as coordenadas entre $30^{\circ} \mathrm{N}$ e $50^{\circ} \mathrm{N}$ e $20^{\circ} \mathrm{W}$ e $10^{\circ} \mathrm{E}$.

Da estação das Penhas Douradas foram usadas 4 observações diárias $(0,6$, 12 e 18h) da temperatura do ar, velocidade e direcção do vento. Esta limitação levou a uma redução no número de valores de observação de temperaturas instantâneas analisadas, que passou a corresponder a $1 / 3$ do total das observações disponíveis, uma vez que, para os postos termométricos, se dispunha de 12 observações diárias. É de notar que, mesmo os dados correspondentes às horas acima referidas, extraídas do Boletim Meteorológico Diário, têm muitas lacunas. A informação das reanálises foi recolhida para as mesmas horas de observação das Penhas Douradas, tendo-se procedido à análise das variáveis consideradas representativas das condições meteorológicas regionais no momento da observação, como a direcção do fluxo, a velocidade do vento, a humidade relativa, a pressão, a temperatura potencial, a água precipitável e o parâmetro ómega (velocidade vertical da ascensão das massas de ar).

2 National Center for Environmental Prediction/National Center for Atmospheric Research. 
Foi também calculada a insolação potencial para 3 postos termométricos que ilustram posições topográficas diferentes: o Cântaro Gordo, em situação de crista, o vale do Zêzere que representa a posição dos fundos de vale com orientação N-S e o fundo de vale da Candieira, que exemplifica os vales com orientação W-E. Para cada um dos locais, foi construído o diagrama solar com a projecção do relevo e calculado o número potencial de horas de sol. Estas variáveis visam estimar a influência que a sombra potencial poderá ter tido nos diferentes locais.

Por fim, criaram-se variáveis relativas à frequência dos 4 padrões térmicos identificados para diferentes horas do dia: madrugada (das 06h às 08h), dia (das $10 \mathrm{~h}$ às $14 \mathrm{~h}$ ), tarde (das $16 \mathrm{~h}$ às $18 \mathrm{~h}$ ) e noite (das $20 \mathrm{~h}$ às $4 \mathrm{~h}$ ).

Com base nos resultados da análise de variância foi aplicada uma análise discriminante aos quatro grupos de horas, para avaliar os factores topográficos e meteorológicos responsáveis pelos padrões encontrados.

\section{RESULTADOS}

\section{As características dos padrões térmicos}

Às diferenças de temperatura entre o Cântaro Gordo e os outros postos aplicou-se uma classificação em $k$-means, definindo 4 clusters de referência, com base na sua frequência de ocorrência, de forma a que a distância entre os membros do mesmo grupo fosse inferior à distância entre os clusters de grupos diferentes (Wilks, 1995). A partir da separação em 4 clusters, foram identificados 4 tipos de padrões (fig. 2).

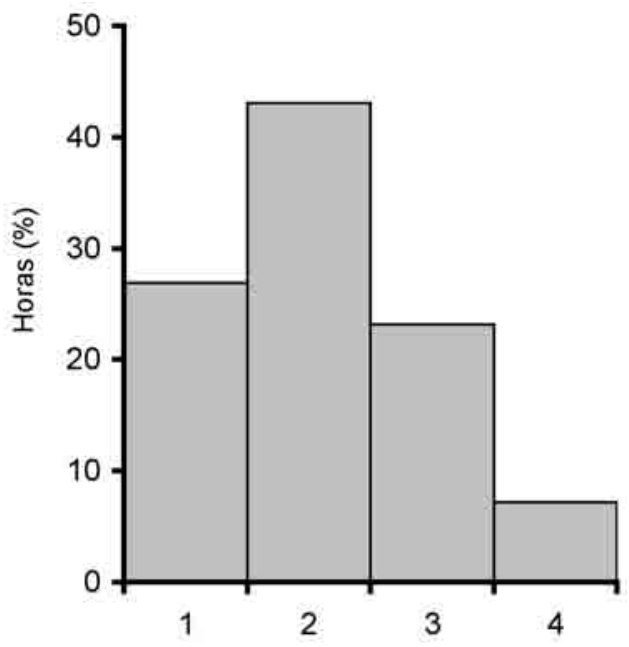

Fig. 2 - Frequência dos padrões térmicos do ar para o ano 2000. Fig. 2 - Frequency of the air temperature patterns during 2000. 


\section{Fundos de vale mais frios (Padrão 1)}

O padrão 1 representa $27 \%$ do total das observações e é constituído pelos episódios em que o Cântaro Gordo registou temperatura mais elevada do que os outros postos, em particular em relação aos postos de fundo de vale (fig. 3a). A mediana das diferenças de temperatura ao Cântaro Gordo é negativa, o que significa que os outros postos registaram temperaturas mais baixas. A temperatura é mais baixa nos fundos de vale, mas o factor altitude também é importante, uma vez que os fundos de vale situados a maior altitude registaram temperaturas inferiores às dos vales a menor altitude. No fundo do vale da Candieira, a mediana das diferenças de temperatura ao Cântaro Gordo, foi de $-5^{\circ} \mathrm{C}$. No fundo do vale do Zêzere, situado $795 \mathrm{~m}$ abaixo do Cântaro Gordo, a acumulação de ar frio foi menos intensa $\left(-1,7^{\circ} \mathrm{C}\right)$, isto porque durante a descida, o ar frio sofre compressão adiabática, aquecendo.

O padrão 1 ocorreu ao longo de todo o ano, mas foi mais frequente em Janeiro, Fevereiro e nos meses de Verão (quadro I). É um padrão associado a condições de estabilidade atmosférica, verificando-se inversões térmicas nas áreas deprimidas. Trata-se, por isso, de um padrão que ocorreu principalmente durante a noite e de madrugada, entre as 20 e as 10h (fig.4).

Quadro I - Frequência de ocorrência dos padrões térmicos durante o ano de 2000. Table I - Monthly frequency of the thermal patterns during 2000.

\begin{tabular}{lcccc}
\hline & Padrão 1 & Padrão 2 & Padrão 3 & Padrão 4 \\
\hline Janeiro & 159 & 0 & 169 & 15 \\
Fevereiro & 179 & 182 & 0 & 0 \\
Março & 109 & 95 & 124 & 0 \\
Abril & 49 & 154 & 0 & 0 \\
Maio & 32 & 281 & 0 & 19 \\
Junho & 134 & 124 & 107 & 33 \\
Julho & 101 & 250 & 0 & 56 \\
Agosto & 126 & 226 & 0 & 36 \\
Setembro & 65 & 200 & 0 & 103 \\
Outubro & 103 & 92 & 177 & 24 \\
Novembro & 9 & 52 & 295 & 0 \\
Dezembro & 0 & 72 & 56 & 0 \\
\hline
\end{tabular}




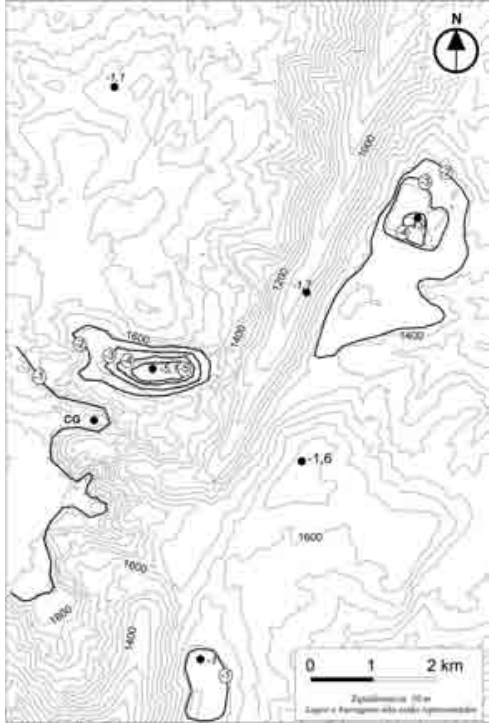

a) Padrão 1 - Fundos de vale mais frios

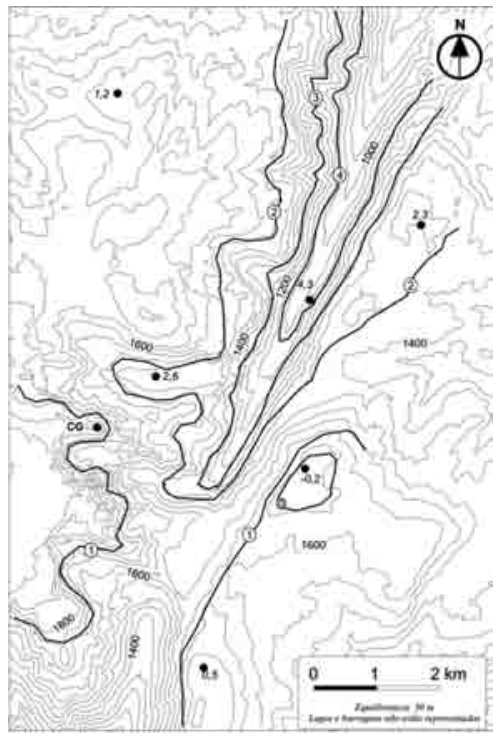

c) Padrão 3 - Planalto oriental mais frio

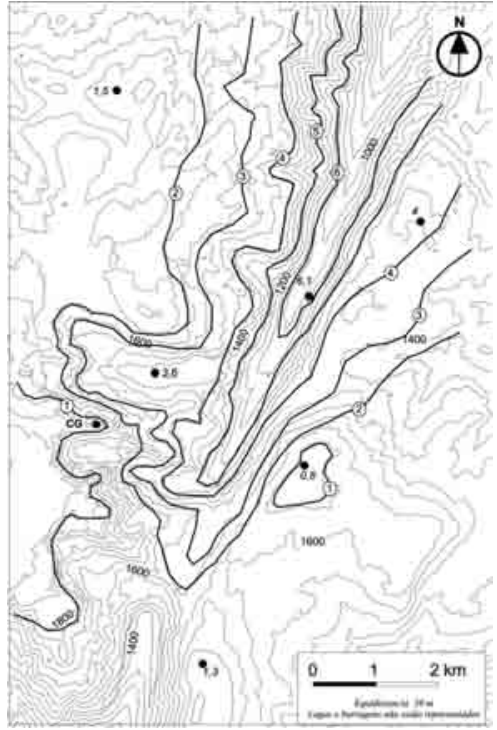

b) Padrão 2 - Planaltos mais frios

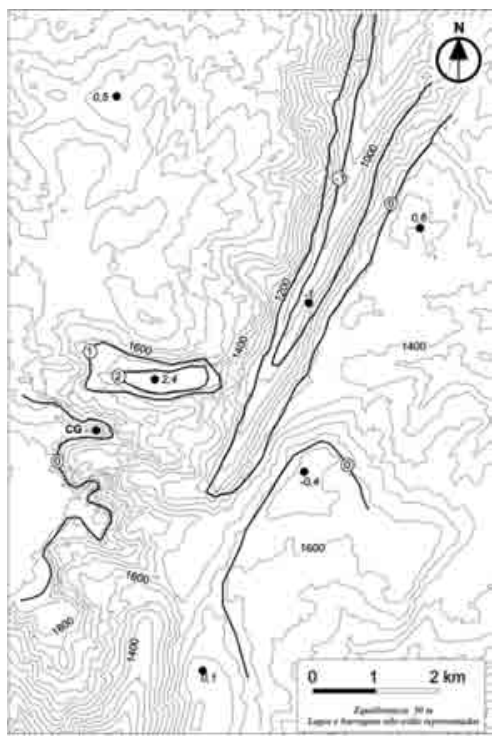

d) Padrão 4 - Acumulação de ar frio no Vale do Zêzere

Fig. 3 - Mediana das diferenças horárias da temperatura do ar entre os postos termométricos e o Cântaro Gordo (CG). a) padrão 1, b) padrão 2, c) padrão 3 e d) padrão 4. As diferenças negativas significam que o posto do Cântaro Gordo está mais quente.

Fig. 3 - Hourly air temperature median differences between the measuring sites and Cântaro Gordo (CG). a) pattern 1, b) pattern 2, c) pattern 3 e d) pattern 4. Negative differences represent higher temperatures at Cântaro Gordo. 


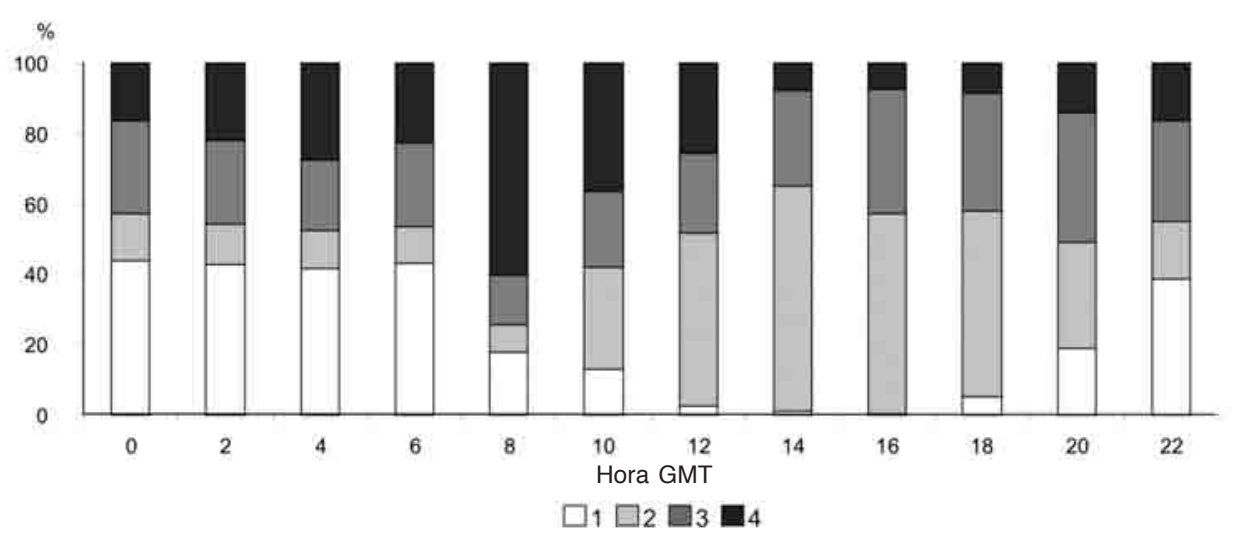

Fig. 4 - Frequência de ocorrência dos padrões térmicos.

Fig. 4 - Frequency of the temperature patterns.

\section{Planaltos mais frios (Padrão 2)}

No padrão 2 agrupam-se as observações em que o Cântaro Gordo esteve mais frio do que os outros postos, diminuindo a temperatura com a altitude (fig.3b). Os fundos de vale estão mais quentes e o do Zêzere registou uma mediana $6^{\circ} \mathrm{C}$ mais quente que o planalto. Nos interflúvios a temperatura do ar varia em função da altitude.

O padrão 2 foi o mais frequente, com $43 \%$ dos casos e ocorreu em todos os meses, com excepção de Janeiro (fig. 2 e quadro I). Teve maior frequência nos meses mais quentes e de dia, entre as 10 e as $22 \mathrm{~h}$ (fig. 4).

\section{Planalto Oriental mais frio (Padrão 3)}

Nos episódios do padrão 3, o posto dos Poios Brancos esteve mais frio do que todos os outros. É um conjunto de observações que tem uma elevada percentagem de ocorrência $(23 \%)$, o que as torna especialmente significativas (fig. 2).

No padrão 3 a temperatura diminui com a altitude a uma taxa inferior à do padrão 2 e a mediana das diferenças de temperatura entre o fundo de vale do Zêzere e o Cântaro Gordo é de $4,3^{\circ} \mathrm{C}$ (fig. $3 \mathrm{c}$ ). O padrão 3 ocorre a qualquer hora do dia, o que traduz um carácter de instabilidade atmosférica (fig. 4). Na amostragem utilizada os eventos com este comportamento ocorreram predominantemente nos meses de Janeiro e de Novembro (quadro I). 


\section{Acumulação de ar frio no Vale do Zêzere (Padrão 4)}

O padrão 4 agrupa as situações em que o posto situado no Vale do Zêzere (ASE), a menos $795 \mathrm{~m}$ do que o Cântaro Gordo, esteve mais frio. Correspondendo a $7 \%$ das observações, teve maior frequência entre as 8 e as 10 h (fig. 2 e 4), principalmente entre Maio e Outubro (quadro I).

Neste padrão, a temperatura no Vale do Zêzere foi, em $50 \%$ dos casos, $1^{\circ} \mathrm{C}$ mais baixa do que a do Cântaro Gordo (fig. 3d). É um padrão que está associado a inversões térmicas no fundo do vale do Zêzere, que só terminam quando o local deixa de estar à sombra e recebe radiação solar directa. De facto, observouse que, ao longo de todo o ano, enquanto o fundo do vale do Zêzere estava à sombra, as outras áreas deprimidas estudadas (Curral da Nave o Fundo de vale da Candeira, fig. 1) já recebiam radiação solar directa e, por isso, registavam temperaturas mais elevadas.

A importância da orientação dos vales na distribuição da temperatura do ar está bem patente no padrão 4. No vale do Zêzere, as inversões térmicas mantêmse durante a manhã até mais tarde devido à sua orientação N-S, enquanto nos vales com orientação $\mathrm{W}-\mathrm{E}$ o ar frio se dissipa mais cedo.

\section{Factores condicionantes dos padrões térmicos}

Como forma de avaliar os factores topográficos e meteorológicos que determinaram a classificação dos padrões térmicos obtida, aplicou-se uma análise de variância (One-way ANOVA forward stepwise) sobre a classificação. Do grupo de variáveis consideradas, todas elas são significativas para $\mathrm{p}<0,05$. Destacam-se o parâmetro ómega, que diz respeito à velocidade de ascensão das massas de ar e a frequência de ocorrência dos padrões à tarde (quadro II).

O padrão 1 ocorre sobretudo durante a noite $(0 \mathrm{~h})$. Este padrão está relacionado com uma pressão atmosférica média mais elevada, menor velocidade média do vento, menor quantidade de água precipitável média na troposfera, e valor médio de ómega positivo, o que indica que não houve movimento ascendente das massas de ar na mesoescala. Ao contrário do anterior, nas ocasiões em que ocorreu o padrão 2, o valor médio de ómega era negativo, o que indica a ocorrência de movimentos ascendentes. Este padrão teve lugar durante a parte mais quente do dia (entre as 12 e as $18 \mathrm{~h}$ ), período em que a camada turbulenta está mais desenvolvida. Por ser um padrão predominantemente diurno, a humidade relativa é menor e a temperatura potencial maior. O padrão 3 ocorreu a qualquer hora e esteve associado a um ómega negativo, elevada humidade relativa e condições de instabilidade atmosférica e de vento forte.

Por último, o padrão 4, pouco frequente, ocorreu no conjunto de horas com maior insolação potencial no vale da Candieira. 
Quadro II - Resultados da One-way ANOVA (médias das variáveis meteorológicas e topográficas para cada um dos padrões; não são apresentadas as variáveis que apresentam variância zero). P é o nível de significação $(\mathrm{p}<0.005)$ e $\mathrm{F}$ é o coeficiente entre a variação das médias num grupo e a variação média esperada. Variáveis meteorológicas obtidas do NCEP/ NCAR: humidade relativa; velocidade do vento; direcção do vento de N, E, SE, S, W e NW; ómega; água precipitável; pressão atmosférica e temperatura potencial. Variáveis meteorológicas retiradas da estação meteorológica das Penhas Douradas: direcção do vento de NW e calma. Variáveis topográficas: insolação nos planaltos, insolação no vale N-S e no vale W-E. Variáveis que indicam a frequência de ocorrência dos padrões de noite (20h-04h), de madrugada (06h-08h), de dia (10h-16h) e de tarde (16h-18h).

Table II - Results of the One-way ANOVA (means of the meteorological and topographic variables for each pattern; variables with zero variance are not represented). $P$ is the significance value $(p<0.005)$ and $F$ is the coefficient between the average of a group and the expected value means. Meteorological variables obtained from the NCEP/NCAR: relative humidity; wind speed; wind direction from $N, E, S E, S, W$ and $N W$; omega; precipitable water; atmospheric pressure and potential temperature. Meteorological variables from the Penhas Douradas meteorological station: wind direction from $\mathrm{NW}$ and calm. Topographical variables: sunshine duration in the plateaus; sunshine duration in the $N-S$ valley floors and in the W-E valley floors. Variables related to the pattern's frequency at night (20h-04h), early morning (06h-08h), day time (10h-16h) and afternoon (16h-18h).

\begin{tabular}{lcccccc}
\hline & $\mathbf{1}$ & $\mathbf{2}$ & $\mathbf{3}$ & $\mathbf{4}$ & $\mathbf{F}$ & $\mathbf{P}$ \\
\hline Humidade Relativa (\%) & 82 & 66 & 86 & 80 & 37,7 & 0,00 \\
Velocidade Vento (m/s) & 3,9 & 4,9 & 5,3 & 3,9 & 57,9 & 0,00 \\
Vento - N & 0,04 & 0,0 & 0,0 & 0,01 & 14,9 & 0,00 \\
Vento - E & 0,4 & 0,3 & 0,4 & 0,4 & 7,5 & 0,00 \\
Vento - SE & 0,05 & 0,2 & 0,1 & 0,1 & 27,9 & 0,00 \\
Vento - S & 0,07 & 0,3 & 0,3 & 0,1 & 104,5 & 0,00 \\
Vento - W & 0,2 & 0,06 & 0,09 & 0,19 & 48,5 & 0,00 \\
Vento - NW & 0,2 & 0,06 & 0,1 & 0,1 & 58,3 & 0,00 \\
Ómega (Pa ${ }^{-1}$ ) & 0,1 & $-0,03$ & $-0,01$ & 0,08 & 317,6 & 0,00 \\
Água precipitável (kg/m $\left.{ }^{2}\right)$ & 13 & 16,6 & 15,6 & 14,5 & 78,1 & 0,00 \\
Pressão & 970,3 & 966,4 & 966,7 & 968 & 106 & 0,00 \\
Temp. potencial (K) & 287 & 294 & 287 & 289 & 75 & 0,00 \\
Padrão - Noite & 0,2 & 0,04 & 0,1 & 0,1 & 58 & 0,00 \\
Padrão - Madrugada & 0,1 & 0,04 & 0,1 & 0,1 & 89 & 0,00 \\
Padrão - Dia & 0,01 & 0,1 & 0.1 & 0,1 & 97 & 0,00 \\
Padrão - Tarde & 0,02 & 0,1 & 0,1 & 0,0 & 120 & 0,00 \\
Vento - NW (PD) & 0,1 & 0,2 & 0,1 & 0,03 & 14,3 & 0,00 \\
Calma & 0,1 & 0,01 & 0,01 & 0 & 15,1 & 0,00 \\
Insolação Planaltos & 0,7 & 1,2 & 0,7 & 1,2 & 40 & 0,00 \\
Insolação Vales N-S & 0,2 & 0,7 & 0,4 & 1,0 & 61,7 & 0,00 \\
Insolação Vales W-E & 0,6 & 1,0 & 0,6 & 1,2 & 28,8 & 0,00 \\
\hline
\end{tabular}


As variáveis significativas, representadas no quadro II, foram todas consideradas na análise discriminante. $\mathrm{O}$ objectivo da análise é identificar as variáveis que melhor poderiam prever a ocorrência dos diversos padrões térmicos acima identificados (quadro III). As funções da análise discriminante permitem classificar correctamente $74 \%$ da amostra (quadro IV). Os padrões 1 e 2 foram bem classificados (respectivamente $86 \%$ e $84 \%$ ). Contudo, no caso dos padrões 3 e 4 , a discriminação foi fraca devido ao reduzido número de casos (padrão $3=34 \%$ e padrão $4=23 \%$ ).

A primeira função é responsável por $71 \%$ da discriminação e opõe os eventos nocturnos e diurnos (quadro IV). Os coeficientes estandardizados das variáveis canónicas mostram uma elevada contribuição das seguintes variáveis: água precipitável, pressão atmosférica e, frequência dos padrões à noite e de madrugada. No lado negativo da função, encontram-se as horas com mais água precipitável na baixa atmosfera e com velocidade do vento regional superior. No lado positivo, surgem os padrões com menor frequência à noite e de madrugada e com menor temperatura potencial.

Quadro III - Características das funções discriminantes.

Table III - Characteristics of the discriminant functions.

\begin{tabular}{|c|c|c|c|c|c|c|c|}
\hline \multirow{2}{*}{$\begin{array}{l}\text { Função } \\
\text { discri- } \\
\text { minante }\end{array}$} & \multirow{2}{*}{$\begin{array}{l}\text { Valores } \\
\text { pró- } \\
\text { prios }\end{array}$} & \multirow[t]{2}{*}{$\%$} & \multirow[t]{2}{*}{$\begin{array}{c}\text { Variáveis } \\
\text { discriminantes }\end{array}$} & \multicolumn{2}{|c|}{$\begin{array}{c}\text { Coeficientes } \\
\text { estandardizados das } \\
\text { funções discriminantes }\end{array}$} & \multicolumn{2}{|c|}{$\begin{array}{c}\text { Estrutura factorial } \\
\text { (corre.-variáveis-scores } \\
\text { canónicos) }\end{array}$} \\
\hline & & & & Raiz 1 & Raiz 2 & Raiz 1 & Raiz 2 \\
\hline 1 & 1,06 & 71 & Omega & $-0,1$ & $-0,1$ & $-0,5$ & $-0,2$ \\
\hline \multirow[t]{14}{*}{2} & 0,21 & 41 & Temperatura potencial & $-0,3$ & 1,6 & 0,3 & 0,5 \\
\hline & & & Padrões de noite & $-0,8$ & 0,3 & $-0,3$ & 0,1 \\
\hline & & & Padrões de madrugada & $-0,8$ & 0,4 & $-0,3$ & 0,08 \\
\hline & & & Pressão atmosférica & $-0,29$ & 0,5 & $-0,3$ & 0,04 \\
\hline & & & Água precipitavel & 0,48 & $-0,4$ & 0,3 & 0,4 \\
\hline & & & Insolação Vale W-E & 0,17 & $-0,7$ & 0,1 & $-0,06$ \\
\hline & & & Humidade Relativa & $-0,2$ & 0,8 & $-0,23$ & $-0,2$ \\
\hline & & & Vento NW & 0,1 & 0,2 & 0,09 & 0,1 \\
\hline & & & Vento NW (PD) & $-0,2$ & 0,1 & $-0,2$ & $-0,1$ \\
\hline & & & Vento W & $-0,2$ & 0,1 & $-0,2$ & $-0,1$ \\
\hline & & & Velocidade Vento & 0,1 & $-0,1$ & 0,1 & $-0,2$ \\
\hline & & & Vento $\mathrm{N}$ & $-0,06$ & 0,1 & $-0,1$ & 0,15 \\
\hline & & & Insolação Interflúvio & $-0,07$ & 0,6 & 0,1 & 0,007 \\
\hline & & & Calma & $-0,006$ & 0,1 & $-0,06$ & 0,1 \\
\hline
\end{tabular}


Quadro IV - Previsão dos grupos com a análise discriminante. Table IV - Predicted classification from the discriminant analysis.

\begin{tabular}{lccccc}
\hline \multicolumn{5}{c}{ Classificação prevista para cada padrão } \\
\hline Grupo actual & Padrão I & Padrão II & Padrão III & Padrão IV & Percentagem prevista \\
\hline Padrão I & 162 & 17 & 8 & 1 & 86 \\
Padrão II & 30 & 236 & 13 & 1 & 84 \\
Padrão III & 26 & 37 & 33 & 2 & 34 \\
Padrão IV & 6 & 8 & 6 & 6 & 23 \\
\hline Total & 224 & 298 & 60 & 10 & 74 \\
\hline
\end{tabular}

A segunda função é responsável por $41 \%$ da discriminação e opõe os eventos de acordo com a temperatura potencial, humidade relativa, água precipitável e insolação nos interflúvios. Do lado positivo surgem as observações com maior temperatura potencial e maior humidade relativa e maior insolação nos fundos de vale com orientação $\mathrm{W}-\mathrm{E}$, e do lado negativo as situações de maior instabilidade e menor insolação.

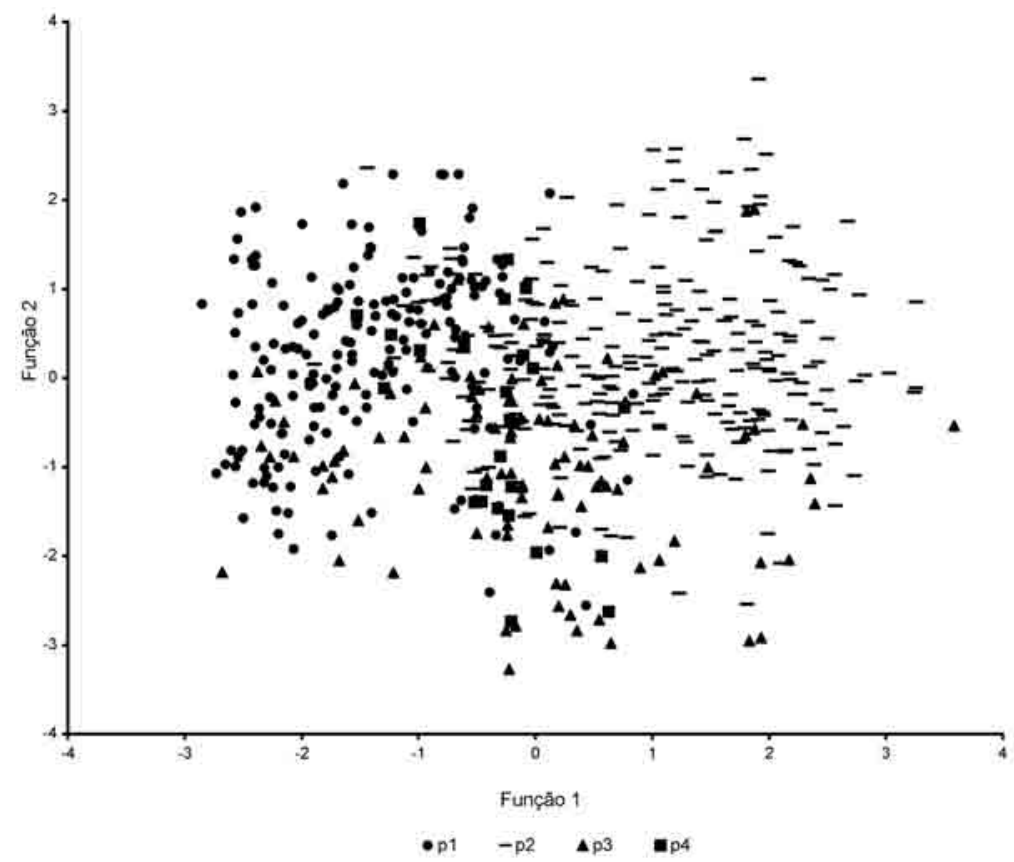

Fig. 5 - Projecção dos scores canónicos dos padrões segundo as 2 funções

P1 - padrão1, P2 - padrão 2; P3 - padrão 3 e P4 - padrão 4.

Fig. 5 - Pattern canonical scores for functions 1 and 2

P1 - pattern 1; P2 - pattern 2; P3 - pattern 3 and P4-pattern 4. 
A projecção dos scores canónicos dos padrões segundo as funções 1 e 2 está representada na figura 5. A função 1 discrimina os eventos nocturnos e diurnos e a função 2 os eventos de acordo com a temperatura potencial, humidade relativa e água precipitável. Observa-se que o padrão 1 se situa do lado negativo da função 1 e o padrão 2 do lado positivo, e que os padrões 3 e 4 estão dispersos pelos eixos, com uma tendência para o padrão 3 se situar do lado negativo da função 2 .

\section{CONCLUSÃO}

A instalação de uma rede de postos termométricos automáticos na Serra da Estrela durante o ano de 2000 permitiu conhecer melhor os padrões térmicos do Alto Vale do Zêzere, bem como os principais factores que os condicionam. A partir de dados bi-horários da temperatura do ar foram identificados os principais padrões térmicos e a sua frequência. Em $66 \%$ dos casos a temperatura do ar foi mais baixa nos interflúvios do que nos vales, em $34 \%$ das ocasiões ocorreu acumulação de ar frio nos vales (eventos nocturnos) e, em 7\% destes, a acumulação de ar frio no vale do Zêzere manteve-se durante a manhã devido ao efeito de sombra.

A análise estatística efectuada demonstrou que os principais factores que controlam os padrões da temperatura do ar são o regime da insolação, a velocidade do vento, a humidade do ar, a ascensão das massas de ar (quantificada pelo parâmetro ómega) e a quantidade de água disponível para a precipitação. Estes são parâmetros que traduzem o carácter de maior ou menor estabilidade da atmosfera no momento das observações.

A interpretação dos padrões térmicos bi-horários mostrou que as situações de acumulação de ar frio se registaram ao longo do todo o ano, embora tenha testemunhado o predomínio da diminuição das temperaturas do ar com a altitude. Para além dessas duas situações, a análise dos dados aponta para a importância da topografia, em particular para o efeito de sombra nos padrões de distribuição da temperatura do ar. Este aspecto é muito significativo quando se pretende extrapolar os resultados para outras serras ou vales. Outro aspecto interessante, mas que não foi possível justificar com base nas variáveis utilizadas, foi o padrão 3 , no qual o planalto oriental, apesar de se situar a menor altitude, esteve mais frio do que o ocidental. Essa situação poderá ser abordada no futuro com a instalação de uma rede de estações meteorológicas mais densa nos planaltos, de forma a estudar o efeito da topografia na deslocação das massas de ar. Acrescenta-se que a importância da orientação do relevo da Serra da Estrela em relação às massas de ar, já foi apontada por Daveau (1977), como tendo efeitos importantes na distribuição da precipitação.

Os resultados apresentados mostram bem a importância da orientação dos vales no seu regime térmico e, neste caso, na duração das inversões térmicas. Os dados mostraram que no vale com direcção norte-sul, como é o caso do vale 
do Zêzere a montante de Manteigas, se verificaram situações em que a inversão térmica permaneceu durante um período longo durante a manhã devido à persistência da sombra. Pelo contrário, nos vales de orientação este-oeste, como é o caso do vale da Candieira, o lago de ar frio e a inversão térmica a ele associado dissipa-se rapidamente. Este é um aspecto interessante a considerar, por exemplo, no ordenamento do território e em estudos de avaliação de impacte ambiental ligados à dispersão de poluentes.

\section{AGRADECIMENTOS}

A autora agradece aos revisores científicos anónimos as sugestões e comentários efectuados ao artigo, que contribuíram para clarificar a redacção final.

\section{BIBLIOGRAFIA}

Alcoforado M J (1994) A vegetação como indicador dos ventos dominantes. Anais do Instituto Superior de Agronomia, XLV: 667-681.

Alcoforado M J (1984) Representação cartográfica das árvores deformadas. Ventos dominantes em torno da Serra de Sintra. Finisterra - Revista Portuguesa de Geografia, XIX(38): 137-169.

Alcoforado M J, Alegria M F, Pereira A, Sirgado C (1993a) Domínios bioclimáticos em Portugal definidos por comparação dos índices de Gaussen e de Emberger. L.A.G.F., CEG, Rel. nº 33, Lisboa.

Alcoforado M J, Andrade E, Neves M, Vieira G (1993b) Climas locais da Arrábida no Inverno. Finisterra - Revista Portuguesa de Geografia, XXVIII(55-56): 215-228.

Daveau S (1985) Mapas climáticos de Portugal: nevoeiro e nebulosidade. Contrastes térmicos. Mem. C.E.G., $n^{\circ}$ 7, Lisboa.

Daveau S, Coelho C, Costa V, Carvalho L (1977) Répartition et rythme des précipitations au Portugal. Mem. C.E.G. $\mathrm{n}^{\mathrm{o}}$ 3, Lisboa.

Hogan A, Ferrick M (1997) Winter morning air temperature. Journal of Applied Meteorology, 36: $52-69$.

Mora C (2006) Climas da Serra da Estrela. Características regionais e particularidades locais dos planaltos e do alto vale do Zêzere. Dissertação de Doutoramento, Universidade Lisboa, Lisboa.

Mora C (1998) Aspectos do clima local da Arrábida. Dissertação de Mestrado, Universidade de Lisboa, Lisboa.

Pepin N, Losleben M (2002) Climate change in the Colorado rocky mountains: free air versus surface temperature trends. International Journal of Climatology, 22: 311-329.

Vieira G T, Mora C, Ramos M (2000) Registadores automáticos de baixo-custo para a monitorização de temperaturas do ar, da rocha e do solo. Finisterra - Revista Portuguesa de Geografia, XXXV(69): 139-148.

Wilks D S (1995) Statistical methods in the atmospheric sciences. Academic Press. 